\title{
The Achilles heel of climate-smart agriculture
}

Article

Accepted Version

Hellin, J. and Fisher, E. (2019) The Achilles heel of climatesmart agriculture. Nature Climate Change, 9. pp. 493-494. ISSN 1758-678X doi: https://doi.org/10.1038/s41558-0190515-8 Available at https://centaur.reading.ac.uk/83848/

It is advisable to refer to the publisher's version if you intend to cite from the work. See Guidance on citing.

To link to this article DOI: http://dx.doi.org/10.1038/s41558-019-0515-8

Publisher: Nature

All outputs in CentAUR are protected by Intellectual Property Rights law, including copyright law. Copyright and IPR is retained by the creators or other copyright holders. Terms and conditions for use of this material are defined in the End User Agreement.

\section{www.reading.ac.uk/centaur}

\section{CentAUR}

Central Archive at the University of Reading

Reading's research outputs online 


\section{The Achilles heel of Climate-smart agriculture}

Jon Hellin, Sustainable Impact Platform, International Rice Research Institute (IRRI), Los Baños, Laguna 4031, Philippines.

Eleanor Fisher, School of Agriculture, Policy and Development, University of Reading, Reading RG6 6AH, United Kingdom.

\section{Climate-adapted agriculture needs to be equitable and inclusive to overcome trade-offs with the Sustainable Development Goals (SDGs). The challenge is to acknowledge power imbalances and socio-economic inequalities and to empower farmers to embrace change in ways that lead to positive agricultural and non-agricultural livelihood transformation.}

In 2015 the United Nations formally adopted the 2030 Agenda for Sustainable Development. Seventeen Sustainable Development Goals (SDGs) were underpinned by the pledge "no one will be left behind" by ensuring that sustainable development is equitable and inclusive ${ }^{1}$. The achievement of many SDGs is dependent on the fostering of a climatesmart food system to feed a growing population, provide secure livelihoods and conserve natural resources ${ }^{2}$. The agricultural sector faces a unique challenge: to increase food production while reducing greenhouse gas emissions caused by food production. Such action is critical given projections that global poverty could increase by anywhere between 35 and 122 million people under climate change scenarios, largely due to negative impact on agricultural incomes ${ }^{3}$. Sustainable management of agriculture is a requirement of sustainable development ${ }^{4}$.

In response, agricultural researchers have developed agricultural technologies and practices, known collectively as Climate-smart agriculture (CSA). These include drought-tolerant crop varieties and improved land management practices. Three pillars form the basis of CSA: that it enhances farmers' ability to adapt to a changing climate; mitigates the emissions of greenhouse gases; and contributes to food security plus broader development goals. CSA is seen as critical to building the resilience of food production systems to climate change as part of efforts to realize SDG \#13 on Climate Action. Evidence suggests that it builds resilience and improves food security ${ }^{5}$. Development agencies have invested in scaling CSA to have wider impact.

CSA aficionados acknowledge that there are trade-offs between these three pillars ${ }^{6}$. In the quest to minimize these trade-offs, and to secure a 'triple win' of food security, adaptation and mitigation, there is an a priori premise that CSA contributes to broader development goals. This ignores, however, 'higher-level' trade-offs between CSA and some of the SDGs, specifically: \#1 No Poverty, \#5 Gender Equality and \#10 Reduced Inequalities ${ }^{7}$. Within a 
depoliticized CSA agenda, these trade-offs are not given the attention they deserve, raising the danger of unintended consequences including perpetuating poverty and reinforcing inequality.

\section{Inequality and poverty among farmers}

CSA efforts are targeted at climate change hotspots based on climate modelling. Less attention is paid to the heterogeneity of farmers and farming conditions in these hotspots, including the vulnerabilities of specific groups, or to how CSA relates to broader development challenges facing these farmers, which may be rooted in unequal power relations and entrenched inequalities.

Many farmers have benefited from CSA $^{8}$ but there is limited evidence that CSA adoption has enabled significant numbers of very poor farmers to escape poverty ${ }^{9}$ even though it is the poor who are most impacted by climate change ${ }^{10}$. Indeed, in rain-fed agriculture, which is particularly vulnerable to climate change, there are farmers for whom agricultural-based livelihoods are so precarious that even 'climate-proofing' their agricultural systems will not contribute to poverty reduction, let alone significant improvements in food security. For these farmers, continuing in agriculture represents little more than a persistence of poverty.

CSA is most likely to be a pathway from poverty for those farmers who are able to increase farm size and/or have access to markets in order to capitalize on new agricultural technologies and practices ${ }^{11}$. Increasing farm size is still possible in some parts of Africa but is less feasible in South Asia. In parts of Latin America, historic inequality in land distribution stymies the agricultural sector's contribution to poverty reduction. For example in the Western Highlands of Guatemala, land availability is 0.06 ha per person; poverty is endemic and farm households produce maize (the main staple crop) for fewer than seven month' consumption per year, with the majority of farmers seeking off-farm employment ${ }^{12}$.

Poverty within agricultural populations is reinforced by inequality and is linked to group specific vulnerabilities. This is illustrated by gender inequalities bound to the inferior status of women in agriculture. In developing countries, women are a substantial proportion of the agricultural workforce and are central to food processing and preparation. Women's contribution to agriculture depends on their access to land but they are disadvantaged due to male bias when it comes to features such as land inheritance, insurance and use of land as collateral. Women also have poor access to agricultural inputs and markets; disadvantages that multiply with climate change ${ }^{13}$. Furthermore, gender inequalities can be reproduced in how women access and benefit from $\mathrm{CSA}^{14}$.

Inequalities extend beyond gender in society-specific ways. For example, in India, farmers belonging to marginalized castes have less access to public extension services that may facilitate increase annual crop income. Likewise, model farmers used to disseminate improved farming practices, including CSA, become power brokers controlling access to 
opportunities, thus reinforcing inequalities by favouring male and excluding female farmers ${ }^{15}$.

The promotion of CSA is accompanied by an emphasis on numbers in response to strategic policy agendas seeking to scale-up CSA: the number of farmers trained, technologies adopted, and area of land converted to CSA, etc. Numbers per se are useful but they can mask more than they reveal. For example, they say little about development indicators such as gender and social equity, specifically how existing forms of poverty and inequality shape particular climate vulnerabilities and determine farmers' access to CSA or how uptake of CSA accentuates or mitigates these inequalities.

\section{From adaptation to transformation}

Recognition of the social, economic and political realities of agricultural development is critical if CSA is to have continued longevity and relevance within international agendas on climate change action and the SDGs. CSA is designed to address issues of climate change adaption, mitigation and food security/broader development goals. These broader development goals, encapsulated by the SDG pledge to leave no-one behind, mean addressing how existing poverty and forms of inequality play out in farmer uptake of CSA and its subsequent impact within an agricultural population.

Minimizing the trade-offs between CSA and SDGs \#13 Climate Action, \#1 No Poverty, \#5 Gender Equality and \#10 Reduced Inequalities requires climate action to move beyond an adaptation and mitigation discourse to embrace a more radical 'transformative' agenda. A starting point for realizing the SDGs through CSA is the farmers themselves and supporting how different groups of farmers frame the options open to them, including non-agricultural livelihoods. Thus, agricultural intensification and diversification needs to be combined with the creation of non-agricultural opportunities and strengthened rural-urban linkages ${ }^{3}$. This requires 'positive' strategies to build livelihood improvement and avoid supporting options that simply feed into development problems elsewhere, such as urban migration generating ever greater slums and poverty in growing megacities.

Linking CSA to a portfolio of other risk management interventions is also crucial. They may include forms of micro-insurance, for which there is growing emphasis in the United Nations Framework Convention on Climate Change (UNFCCC) processes. In 2015, climate risk transfer was given a significant boost by the Sendai Framework for Disaster Risk Reduction, the COP21 Paris Agreement, and the Group of Seven (G7) InsuResilience initiative aiming to insure an additional 400 million vulnerable individuals against climate risks by 2020 , supported by G7 commitment of USD 550 million.

Social protection is another form of risk-management that may complement or be an alternative to CSA for chronically poor and vulnerable groups. This includes social assistance (cash or in-kind transfers) and/or labour market programs (e.g. unemployment benefits). By alleviating credit, savings and liquidity constraints, such transfers can stimulate agricultural 
production through investment in technology and productive assets, and increased ownfarm household labour allocation?.

Whatever portfolio of interventions are appropriate, the challenge is to start by acknowledging farmers realities and to empower farmers to embrace change in ways that lead to positive livelihood transformation. Supporting constructive agricultural and nonagricultural livelihood transformation requires a deep understanding of farmers' social, cultural, political, and economic circumstances and aspirations. This includes accepting the political dimension of agricultural development, with cognisance of the repercussions of entrenched inequality on farmer uptake of opportunities. Such an approach necessitates innovative cross- and inter-disciplinary research-for-development ${ }^{16}$ to ensure that CSA contributes more to the SDGs. It also requires comprehensive monitoring and evaluation, and impact assessments that go beyond 'headline' numbers to explore the more nuanced impacts of CSA interventions.

Designing and implementing CSA interventions that are equitable and inclusive means recognizing people's differing access to CSA opportunities, and addressing the differential impacts of these interventions on existing poverty levels and inequalities. A particularly challenging proposition is encouraging different actors to work together to overcome deeply entrenched power imbalances that stymie gender and social equity. This applies to society in general, extending beyond the communities of scientists and small-scale farming populations involved in CSA interventions. Failure to do so will do little to mitigate the trade-offs with SDG \#1, \#5 and \#10. These trade-offs are becoming the Achilles heel of CSA and will ultimately undermine CSA's contribution to the realization of sustainable development.

\section{References}

1. Resolution adopted by the General Assembly on 25 September 2015 (UN General Assembly, 2015).

2. Future of Food: Shaping a Climate-smart Global Food System (World Bank Group, 2015).

3. The State of Food and Agriculture 2016 (SOFA): Climate Change, Agriculture and Food Security (United Nations Food and Agriculture Organization, 2016).

4. Smith P. et al. in Climate Change 2014: Mitigation of Climate Change. Contribution of Working Group III to the Fifth Assessment Report of the Intergovernmental Panel on Climate Change (eds Edenhofer, O.R. et al.) Ch. 11, 811-922 (Cambridge University Press, 2015).

5. Lipper, L. et al. Nat. Clim. Chang. 4, 1068-1072 (2014).

6. Thornton, P. K. et al. Agric. Syst. 167, 161-175 (2018).

7. Jagustović, R. et al. Agric. Syst. (2019).

8. Aggarwal, P. et al.. Ecol. Soc. 23, 15 (2018).

9. Hansen, J. et al. Agric. Syst. 172, 28-46 (2019).

10. Hallegatte, S. \& Rozenberg, J. Nat. Clim. Chang. 7, 250-256 (2017). 
11. Harris, D. \& Orr, A. Agric. Syst. 123, 84-96 (2014).

12. Hellin, J., Cox, R. \& López-Ridaura, S. Mt. Res. Dev. 37, (2017).

13. Agarwal, B. Curr. Opin. Environ. Sustain. 34, 26-32 (2018).

14. Tsige, M. Rural Sociology (2019).

15. Taylor, M. \& Bhasme, S. J. Rural Stud. 64, 1-10 (2018).

16. Rigg, J. \& Mason, L. R. Nat. Clim. Chang. 8, 1030-1032 (2018). 